\title{
TRADUCIR LA IDENTIDAD COMO MANTEQUILLA: EL FRANCÉS BEUR
}

\section{TRADUZIR A IDENTIDADE FEITO MANTEIGA: O FRANCÊS BEUR}

\section{José Yuste Frías*}

«Mal nommer les choses, jugeait Camus, csest ajouter au malheur du monde. Ne pas nommer les choses, c'est nier notre humanité.» Eric Fottorino, Suite à un accident grave de voyageur (2013).

\section{RESUMEN}

La palabra francesa arabe («árabe») está en el origen del término francés beur que se creó en verlan para designar a las personas nacidas en Francia cuyos padres o abuelos fueron inmigrantes provenientes del Magreb. Tras una breve descripción sobre cómo se formó dicho término en francés durante la década de los ochenta del siglo pasado, este artículo, primero, se plantea por qué el femenino del mismo es beurette y no beure para luego exponer cómo se han realizado unos muy determinados tipos de traducción de la identidad del Otro en otro tiempo colonizado. Que beur sea el perfecto homófono de beurre (mantequilla) en francés conlleva una serie de consecuencias simbólicas que se resumen en la nula voluntad política del Estado francés de traducir, adecuada y correctamente, todas las pertenencias de la identidad mestiza de las personas nacidas en Francia con orígenes magrebíes, en aras de una supuesta «integración» republicana francesa. Se han creado, en verlan, en el uso popular de la lengua francesa, dos neologismos (beur y beurette) que, dada su dificultad de traducción, han sido exportados a otras lenguas como préstamos léxicos pero su correcta interpretación en las mismas deja mucho que desear. Hacia el final del artículo se presenta una reflexión crítica, a modo de conclusión, sobre los términos beur y beurette como «intraducibles» en el sentido apuntado por Barbara Cassin y se propone cómo poder resolver la aparente contradicción de traducir «lo intraducible» cuando quien traduce e interpreta sabe situarse «entre» lenguas y culturas, gracias a la noción de paratraducción.

Palabras clave: identidad; paratraducción; ${\text { transculturalidad; } \text { mestizaje }_{\text {; }} \text { bur }}_{\text {; beurette. }}$

\section{RESUMO}

A palavra francesa arabe («árabe») está na origem do termo francês beur que foi criado em verlan para designar as pessoas nascidas na França cujos pais ou avós eram imigrantes vindos do Magrebe. Depois de uma breve descrição sobre como esse termo foi formado dentro da língua francesa durante a década de oitenta do século passado, este artigo começará questionando a razão de a forma feminina ser beurette e não beure. Na sequência, apresentaremos

\footnotetext{
* Universidade de Vigo, Espanha. jyuste@uvigo.es

Orcid: https://orcid.org/0000-0002-2102-3901
} 
como alguns tipos muito específicos de tradução da identidade do Outro foram realizadas em outros tempos colonizados. O fato de beur ser um homófono perfeito de beurre (manteiga) em francês acarreta uma série de consequências simbólicas que se resumem na nula vontade política do governo francês de traduzir, adequada e corretamente, todos os pertencimentos da identidade mestiça das pessoas nascidas na França com origens magrebinas, em prol de uma suposta "integração" republicana francesa. Assim, no uso coloquial da língua francesa, foram criados, em verlan, dois neologismos (beur e beurette) que, dada a sua dificuldade de tradução, foram exportados para outras línguas como empréstimos lexicais, mas a correta interpretação desses termos deixa muito a desejar. No final do artigo, apresentamos uma reflexão crítica, a título de conclusão, sobre os termos beur e beurette como «intraduzíveis» no sentido apontado por Barbara Cassin, propondo como podemos resolver a aparente contradição de traduzir «o intraduzível» quando quem traduz e interpreta sabe situar-se «entre» línguas e culturas, graças à noção de paratradução.

Palavras-chave: identidade; paratradução; transculturalidade; mestiçagem; beur, beurette.

\section{1. ¿DICCIONARIOS PARA-TRADUCIR LA REALIDAD?}

Desde que el término «familiar» beur apareció en el famoso diccionario Le Petit Robert, por primera vez en la edición de 1985, esto es lo que podemos leer, textualmente, en la definición que aparece en su edición en papel de 1994: Jeune Magrhébin né en France de parents immigrés ( $J$ Joven magrebí nacido en Francia de padres "inmigrados"»). Si el joven beur ha nacido en Francia cpor qué decir que es magrebí... acaso es que no se le considera «francés» por ser hijo de quien es?; ¿̇por qué no haber redactado algo así: Jeune né en France de parents maghrébins immigrés «Joven nacido en Francia de padres magrebíes "inmigrados"»? Que el considerado como el «laboratorio del uso real de la lengua francesa» hubiese ofrecido en los años noventa del pasado siglo esa definición del sustantivo y adjetivo masculino beur insistiendo en una sola de las pertenencias de la identidad de la persona -la «magrebí»- hacía que lo que se supone es la obra de consulta de referencia de todo traductor-intérprete que trabaja con el francés, dejase de ser una ayuda para-traducir la identidad de los hijos (y las hijas) de todas aquellas personas migrantes que, provenientes del norte de África, se habían instalado en Francia desde hace décadas. Si los «jóvenes» beurs habían nacido en Francia, todos tenían (y siguen teniendo), además de una(s) pertenencia(s) propia(s) del seno familiar en el que fueron criados, la nacionalidad francesa como cualquier otra persona nacida en Francia, ni más ni menos. ¿Por qué no decir que el beur es también francés? Desgraciadamente, en la Europa de la no traducción del Otro donde, una y otra vez, se reduce y limita la identidad del migrante (y del hijo del migrante) a una sola y única de sus pertenencias (YUSTE FRÍAS, 2017: en red) eso de que alguien pueda ser «francés» a pesar de sus orígenes no está tan claro. Parece que en Francia haya que elegir siempre entre una dualidad 
permanente: en este caso, o se es magrebí o se es francés. Ya hemos comentado en varios artículos de nuestro Blog de Investigación francófono, Sur les seuils du traduire ${ }^{1}$ cómo la ausencia del paradigma de la traducción en la gestión de la diversidad cultural ha impedido el mestizaje de culturas $y$, por consiguiente, la posibilidad de que la población entienda que se puede ser, en Francia, 100\% magrebí y 100\% francés. El modelo intercultural de integración republicana francés (YUSTE FRÍAS, 2018a) ha querido pasar al beur por el pasapuré de las políticas de migración para que los orígenes del «Joven magrebím pasasen desapercibidos en el espacio público y todo el mundo lo viera como un francés más en la política de migración de la crema de verduras (YUSTE FRÍAS, 2016) practicada durante décadas en Francia. Se ha llegado a formar incluso la palabra beurgeoisie para designar a los beurs que, con su alto estatus social y económico, se han integrado tan bien en el sistema que forman parte de su élite.

Otro detalle que, como Traductor-Intérprete Francés-Español-Francés, me llama poderosamente la atención de la definición del diccionario Le Petit Robert es por qué beur sólo es aplicable a la población juvenil. ¿Acaso no ha habido, hay y seguirá habiendo adultos y ancianos beur en Francia? La actual edición electrónica de Le Petit Robert parece responder al dar hoy esta definición en red del término beur: Personne née en France de parents immigrés magbrébins ( Persona nacida en Francia de padres "inmigrados" magrebíes»). Y cuando parece que la cosa va arreglándose en la era digital, a uno se le ocurre consultar el diccionario Larousse en internet para redactar este artículo y se encuentra esta definición en la que la edad de la persona beur parece seguir siendo importante a la hora de definir el término: Jeune d'origine maghrébine né en France de parents immigrés («Joven de origen magrebí nacido en Francia de padres "inmigrados"»).

[le mot « beur »] se charge en outre de connotations positives telles que jeunesse, dynamisme, ouverture. Ainsi il ne désigne plus seulement un groupe mais un état $\mathrm{d}$ sesprit, une manière d`être ensemble et de vouloir vivre avec, autrement dit une prise de conscience identitaire (ces jeunes sont fiers de leurs origines) et une volonté d'insertion (ils demandent à être reconnus comme égaux et comme frères). (DESPLANQUES, 1997, p. 240)

En el diccionario Larousse, vuelve el «Joven» y se insiste en designar, cuando no connotar, el origen «magrebí» de la identidad de la persona a la que se llama beur, esta vez, desde el principio de la propia definición y no al final como lo hace el diccionario Le Petit Robert.

1. https://seuils.hypotheses.org/ 
Le mot beur illustre de manière remarquable les analyses du phénomène de l'ethnicité, le travail de redéfinition identitaire, le bricolage identitaire des jeunes migrants. Il faudrait une autre étude pour interroger le vocabulaire des sociétés de départ désignant les jeunes issus des migrations [...] Le mot beur a accompagné la trajectoire de la pluriculturalité. Après avoir été connoté de manière positive dans une partie des milieux de gauche, sa vogue et son emploi ont décliné dès la fin des années 1980. Il faut relever que cette vogue du mélange, de toutes les couleurs, a été vigoureusement critiquée par ceux qui se réfèrent au modèle assimilationniste, à l'intégration à la française, qui s'inquiètent du risque de voir se constituer une appartenance communautaire contradictoire avec la citoyenneté, une revendication ethnique contraire à ce modèle. (LIAUZU, 1997, p. 13)

\section{EL ORIGEN DEL TÉRMINO BEUR}

La palabra francesa arabe («árabe») es el origen del término francés beur que se creó durante la década de los ochenta del siglo pasado en verlan, esa forma de argot del francés que traduce todo un universo popular del habla donde lo más importante es no ser comprendido por quien no sea del grupo y que consiste en hablar «al revés» invirtiendo las sílabas de una palabra (à l'envers $={ }^{*}$ vers l'en=verlan) y, algunas veces, provocando incluso la elisión de otras. De la pronunciación de la «e» caduca final de la palabra árabe [aRabə] (tan fuertemente labializada que debería incluso transcribirse así [aRabe]) sale «a-ra-beu» que en el verlan («al revés») de los años 80 en Francia da dos formas diferentes en dos tiempos de creación neológica totalmente diferentes.

Primero, la inversión de la palabra francesa arabe en su esqueleto consonántico R.B. da por aféresis y cambio en la pronunciación final, la palabra «rebeu» [Rəbe]. Una palabra que fue creada para designarse a sí mismos en verlan haciendo referencia explícita al hecho de ser «árabe» sin mencionar ninguna nacionalidad, por esos «jóvenes de origen magrebí»», «inmigrantes de segunda generación» nacidos en un espacio urbano de Francia muy determinado (los barrios de la periferia de París, la banlieue llamados hoy quartiers populares o quartiers prioritaires) que, en realidad, ni eran inmigrantes, ni eran descendientes de inmigrantes sino, más bien, descendientes de personas colonizadas. Estamos ante una expresión «vernacular» que habla de Francia y de su relación con sus minorías provenientes de su pasado colonial. Unas minorías que utilizan una forma de hablar tan genuinamente francesa como es el verlan apropiándosela, sin ambages, con el fin de crear todo un neologismo en la lengua francesa, rebeu, que consideran como proprio, para-traducir su identidad árabe.

Fue bastante más tarde, y nunca antes (como pretende hacernos creer la información que circula por las redes), cuando, por inversión de, esta vez, la 
propia palabra «re-beu» a partir de su raíz de dos letras R.B., se crea el esqueleto consonántico B.R. que, gracias al deslizamiento de la «e» caduca de la sílaba final «be» pronunciada labializada y un poco más abierta al estar colocada entre las dos consonantes invertidas, da la palabra «beur» [bœR]. Recordemos aquí que durante muchos años rebeu era una palabra usada, sólo y exclusivamente, por ese grupo de población que he descrito anteriormente y que se reafirmaba como rebeu cada vez que la pronunciaba. Nadie más en Francia que no perteneciera a ese grupo se atrevía a usar, de forma natural, la palabra rebeu por su eminente carga racial, histórica, colonial y orientalista. Así fue cómo el término rebeu, de nuevo gracias al verlan, se transformó en beur. Una palabra original que al francés no árabe le suena tan exótica como familiar ya que el monosílabo resulta ser el perfecto homófono de la palabra que se utiliza en francés para designar el ingrediente más importante de la gastronomía (del norte) de Francia: la mantequilla... le beurre.

tant l'analogie avec notre beurre, dont les émigrés couvrent leurs tartines, est évidente [...] Lors d'une discussion sur l'immigration, au congrès national de la CFTC en 1987 à Versailles, n'avons nous pas entendu l'un des délégués syndicaux s'écrier au milieu des rires : «Après nous avoir fait bouffer du bougnoule, on veut nous faire bouffer des petits beurs» ? [...] Les jeux de mots sont très nombreux. G. Pierquin fait paraitre en 1987 son roman policier, Le Beur et l'argent du beur. A la même date, mentionnons un article de M. Kaddouni, dans Arabies $n^{\circ} 5$, intitulé «Les petits beurs brisés». (TOURNIER, 2002, p. 17 y nota a pie n. ${ }^{\circ} 20$ )

No me detendré ahora en pensar en la cantidad de juegos de palabras que presta la lengua francesa al racista de turno que le apetezca seguir insultando, humillando y denigrando al hijo del inmigrante del Magreb que considera como «extranjero» a pesar de haber nacido en Francia, utilizando las expresiones más corrientes construidas con la palabra mantequilla (beurre) en francés: Le beurre et l'argent du beurre («querer todo sin dar nada a cambio»); Faire son beurre («ganarse el pan»), Promettre plus de beurre que de pain («prometer mucho más de lo que uno puede llevarse consigo»); Avoir un œil noir («tener un ojo morado»); Comme dans du beurre («se dice de algo muy fácil»); Tu n’as pas inventé le fil à couper le beurre («eres idiota por no decir gilipollas»); Compter pour du beurre («no contar»); Pas plus que du beurre en broche («ninguna probabilidad de que ocurra»); Battre le beurre («pelearse»); etc. ... tan sólo me pregunto, aquí y ahora, si será casualidad que la palabra «mantequilla»-beurreesté separada de la palabra beur en el diccionario Le Petit Robert por una onomatopeya que expresa el asco en francés: beurk. En todo caso, el beur se convierte en la paratraducción rebeu al ser la palabra que puede ser nombrada y usada a troche y moche por la mayoría de los hablantes de la lengua francesa que no tienen orígenes magrebíes o del norte de África. Y, desde la década de los 80, el término beur aparece como adjetivo en una proliferación de expresiones: littérature «beur», radio «beur», etc. 
Pour nous en tenir au mot et aux valeurs dont il était porteur, il convient encore de rappeler que, devenu adjectif (autre preuve de sa vitalité), il a servi à qualifier le mouvement lui-même : on parle alors de mouvance beur; mais aussi les structures qu'il a cherché à se donner : les associations beurs; leur mode d'expression dans le champ de la communication : la presse et les radios beurs, comme dans celui de la culture : le chant, la danse, le cinéma, le théâtre et le roman beurs. (DESPLANQUES, 1997, p. 240-241)

Hasta incluso la famosa Marche pour l'égalité et contre le racisme cuando, del 15 de octubre al 3 de diciembre de 1983, miles de personas de los barrios populares emprendieron una marcha de Marsella a París para denunciar el racismo y la represión policial, será rebautizada por los medios franceses Marche des beurs aplicando a la perfección en el discurso público los elementos de lenguaje utilizados por el poder para «integrar» toda esa juventud de origen norte-africano que quiso tomar al pie de la letra los derechos civiles, sociales y de la ciudadanía que se le estaba enseñando en la Escuela y en los Institutos franceses. Excelente manera de supuestamente «valorizar» un tipo de población para, en realidad, reducirla al silencio y neutralizar sus reivindicaciones. Estamos ante el eterno doble juego del discurso republicano francés sobre la «integración» que, en 1998, con la victoria de Les Bleus en la Copa Mundial de fútbol, consigue llegar a la consagración más positiva de la palabra beur con la creación de la expresión «black-blanc-beur» (YUSTE FRÍAS, 2018a), eslogan y símbolo identitario usado para expresar la máxima integración en la República francesa.

«Black, blanc, beur». On se souvient de l'étiquette multicolore que l'opinion accola aux maillots de l'équipe de France de football en 1998. Indéniablement plus joyeuse que le monochrome «les Bleus », dont l'usage perdure néanmoins - par atavisme royaliste, peutêtre. [...] Ce bariolage joliment allitéré servait la gloire du métissage, crurent certains. Et de louer les vertus de l'intégration républicaine à la mode de chez nous ou du multiculturalisme, American style. Hélas, le tableau social au quotidien ne changea guère et reconduisit sa grisaille -racisme ordinaire, exclusion de toutes sortes, banlieues en friche, chômage...- [...] C'est que le métissage n'est pas l'effet Benetton. (NOUSS, 2005, p. 9)

Parecerá un mero detalle anecdótico de la vida cotidiana, pero seguro que no seré el primero en interpretar que es precisamente eso lo que viene a expresar, de forma indirecta, inconsciente y simbólica, la homofonía entre la palabra beur y la palabra beurre en francés: para-traducir que el hijo de segunda generación del árabe migrante del Magreb o del norte de África -le beur-, que vive en las barriadas desfavorecidas de París, en la banlieue, es un ejemplo perfecto de integración porque utiliza la mantequilla -le beurre - (y no el aceite de oliva) para untar sus rebanadas y tostadas de pan en el desayuno como lo ilustró a la perfección el ilustrador 
Rakidd $^{2}$ hace tres años con una imagen que hace referencia al «único significado» que quisieran muchas personas que tuviera el término beurette (una rebanadita de mantequilla) para que dejara de ser un insulto. Así pues, desde la década de los ochenta del siglo pasado, el término beur se usa en Francia para-traducir una muy determinada identidad. Concretamente para designar al árabe que puede -y debeintegrarse en la sociedad francesa sin fisuras, es decir para-traducir que se puede ser árabe sin todos sus «inconvenientes»... convertirse en un(a) árabe atractivo(a) y seguro(a).

\section{3. ¿POR QUÉ EL FEMENINO DE BEUR ES BEURETTE?}

Es en todo este contexto histórico, social y cultural de creación lingüística del término beur cuando aparece el femenino del mismo: «beurette» [bəRet]. Para quienes traducimos del francés y hacia el francés lo que me interesa destacar aquí, desde la perspectiva de la traducción como paradigma de interpretación de los fenómenos sociales implícitos en el vocabulario utilizado por las personas usuarias de la lengua francesa, es que en lugar de haber formado el femenino de «beur» añadiendo simplemente una «e» y crear, así, el término «beure» (a tan sólo un «r» de ser la grafía de la palabra «mantequilla»-beurre- en francés de la cual es hómofona el masculino beur y lo sería el femenino beure), se añadió el sufijo «-ette». Un sufijo que para todo Traductor-Intérprete de Francés-Español-Francés que se precie, es decir, para quien conoce la lengua francesa mucho mejor que cualquier nativo o nativa (YUSTE FRÍAS, 2014), en un primer momento, es entendido como un sufijo diminutivo supuestamente «cariñoso», pero, muy pronto, se da uno cuenta del juego irónico que hay detrás, $\mathrm{y}$, en un segundo momento, nos vienen a la mente palabras francesas tales como midinette, soubrette cuyo campo semántico subalterno viene a reforzar el imaginario asociado al bajo estatus que tiene designar, por extensión, «jovencitas simples, frívolas y con sentimentalidad naif». Vamos que, haber creado el femenio beurette con ese sufijo «-ette» hace que el nuevo término femenino en cuestión no escape a la connotación simbólica que del propio sufijo acabo de comentar. Se refuerza todavía más, si cabe, la voluntad de dominio y control absoluto sobre la mujer árabe por parte de los medios de comunicación franceses que ya usaban beur en masculino (porque, recuerden, no «podían» usar rebeu) fieles al espíritu de tutela todavía imperante en el imaginario poscolonial que quiere seguir dominando, domesticando, encore et toujours, el pueblo otrora colonizado. Con el

2. https://twitter.com/rakidd/status/891918562725638144?s $=20$ 
término beurette, estaríamos ante una visión de la «mujer árabe» del norte de África totalmente heredera de la «predación sexual del Hombre Europeo» durante el periodo colonial. La Beurette se convierte así en un objeto sexual y, por consiguiente, el término muy pronto conlleva el insulto en su estructura más profunda. De la «morisca» a la beurette, la representación iconográfica recoge siempre los mismos estereotipos orientalistas del heteropatriarcado machista del periodo colonial que considera a la mujer magrebí y del norte de África como una presa sexual. Como muy bien recuerda Pascal Blanchard (BLANCHARD et alii, 2018) la dominación de las tierras se acompaña de la dominación de los cuerpos. El cuerpo del Otro se convierte en objeto de deseo, de violencia, de dolor, de captación: poseer el cuerpo del Otro era como un «derecho del colono» que, ejerciéndolo, no sólo humillaba al colonizado, sino que supuso la puesta en marcha de todo un sistema de predación sexual que ha ido creando, a lo largo de siglos, un imaginario colonial fantasioso de paraíso sexual todavía vigente hoy en día. Las imágenes recopiladas en el magnífico libro redactado por 97 autores, dirigido, entre otros, por Pascal Blanchard y tan acertadamente titulado Sexe, race \& colonies. La domination des corps $d u X V^{e}$ siècle à nos jours, no son imágenes «eróticas» sino más de mil cuadros, ilustraciones, fotografías y objetos de seis siglos de historia de «la dominación colonial y su safari sexual». Son muchos siglos de sexualización fetichista y completa deshumanización de la mujer francesa de origen magrebí por parte de quien nunca se planteó traducir las distintas pertenencias de la identidad (YUSTE FRÍAS, 2013) de una mujer tan francesa como cualquier otra y se limita a reproducir una fantasía sexual tan inconsciente como estereotipada por el propio Delacroix cuando pintó su romántico cuadro orientalista titulado Les femmes d'Alger dans leur appartement en 1833 para expresar en el rostro de las odaliscas (esclavas vírgenes) la «voluptuosa languidez».

Con todo este pasado colonial que impregna profundamente una de las fantasías sexuales más extendidas en Francia, resulta normal que, hoy, la mujer de origen magrebí quiera que se la deje de identificar con una expresión que ve no sólo como peyorativa desde un punto de vista cultural, sino como un grave insulto, sobre todo, cuando se sabe que beurette resulta ser el término utilizado, desde hace más de veinte años, en sitios webs pornográficos francófonos para unos determinados gustos sexuales herederos del imaginario sexual construido al mismo tiempo que el imperio colonial de Francia. No hace falta ir a webs pornográficas para comprobarlo, basta con que uno teclee en Google el término «beurette» y encontrarse con las primeras imágenes que salen en el motor de búsqueda por excelencia. La fotos recopiladas por el algoritmo dejan muy claro el alto grado de vulgaridad que expresa el término beurette cuando es usado por la juventud adolescente magrebí como sinónimo de 
mujer michto (michtoneuse es sinónimo de «prostituta» o mujer que se relaciona con hombres sólo buscando su dinero) a la que sólo le interesa el dinero, el físico y lo superficial. La beurette aparece en la red hipermaquillada, con los labios pintados

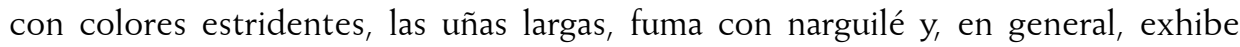
profusamente su físico. Beurette ha pasado de significar la mujer «sumisa» en tiempos coloniales a ser, hoy, sinónimo de mujer «superficial»... la Bimbo sans cervelle tipo la famosa Nabila que se convirtió, de la noche a la mañana, en estrella del programa de telerealidad francés titulado Les Anges de la téléralité por su celebérrima frase «Non mais allo quoi. T'es une fille t'as pas de shampooing... C'est comme si je te dis t'es une fille t'as pas de cheveux» convertida en marca registrada por ella misma tras haber sido parodiada hasta incluso por Ikea. ¿Puede haber un término más peyorativo e insultante?

\section{EL ESCÁNDALO EN TF1 O CUANDO EL USO PEYORATIVO DEL TÉRMINO BEURETTE SE CONVIERTE EN NORMA}

El 31 de mayo de 2020, la cadena TF1 de Francia usó el término beurette para anunciar el episodio 62 de la 13. ${ }^{a}$ temporada, titulado Yasmina, de su serie Joséphine Ange Gardien protagonizada por la actriz Mimie Mathy desde 1997. Un episodio que, por cierto, se emitió por primera vez en 2012 pero la polémica no surgió entonces sino ahora, en 2020. Al parecer, el público francés se llevó las manos a la cabeza cuando descubrió lo palabra beurette y las tres palabras que le seguían en el resumen editado por la cadena. La personaje que da nombre al episodio, Yasmina, es presentada como une jeune magrbébine qui rêve d'intégrer Privela, une grande entreprise de cosmétiques «una joven magrebí que sueña con integrar Privela, una gran empresa de cosméticos». Una vez más, el modelo de integración republicana puesto en pantalla como ejemplo de gestión de la diversidad cultural en Francia. Y para describir a Yasmina se dice, textualmente, que es una beurette issue de banlieue «Joven magrebí nacida en Francia de padres «inmigrados» que viene de la periferia». La expresión beurette issue de banliene resulta ser una tautología, un auténtico pleonasmo porque como he apuntado desde el inicio de este artículo, la beurette está íntimamente unida a la historia de la inmigración poscolonial de los/as descendientes de inmigrantes magrebíes o del norte de África en Francia que han ocupado siempre la periferia de París. ¿Cómo no iba Yasmina a venir de la banlieue? Escribir beurette issue de banliene en el resumen es o bien demostrar la ignorancia supina de la historia de la palabra beurette en francés o bien insistir en una redundancia que ha sido leída como mucho más que agresiva por una gran parte de una parte de la población francesa hoy. Supongo que por todo 
lo dicho en este artículo, el lector entenderá por qué ardieron las redes sociales y, desde el 1 de junio de 2020, el hashtag \#TF1Raciste fuese Trending Topic en Francia.

\section{TRANSCULTURALIDAD Y MESTIZAJE EN EL USO POSITIVO DEL TÉRMINO BEURETTE}

Como suele ocurrir casi siempre con todo elemento con fuerte carga simbólica, muy pronto tenían que aparecen significados del término beurette totalmente contrarios a todo lo expuesto hasta el párrafo anterior. En efecto, porque siempre connota mucho más que denota, beurette puede convertirse también en un término usado de forma positiva y reivindicativa, tal y como hace la artista y estilista Lisa Bouteldja ${ }^{3}$ al reapropiarse el término calificándose a sí misma de beurette para impedir que otros la llamen así y le coloquen la etiqueta con todos sus significados peyorativos e insultantes. Se trata de todo un vuelco semántico en el que Lisa Bouteldja imita lo que los militantes negros americanos hicieron con los términos nigger o black: otrogar al término beurette toda la positividad que no había tenido hasta entonces, con todas las repercusiones éticas, sociales, políticas y culturales que ello pueda suponer en la Francia de hoy. Lisa Bouteldja reivindica sus orígenes argelinos y se viste como quiere sin dar la imagen de haber caído en los estereotipos de la beurette comentados más arriba. Para conseguir su objetivo, utiliza siempre la moda como arma simbólica con el fin primordial de expresar su identidad mestiza. Todo un trabajo de desconstrucción permanente de los códigos de la vulgaridad y de los estereotipos culturales peyorativos creados alrededor la mujer magrebí etiquetada en Francia con el término beurette. Lisa Bouteldja utiliza fotos y vídeos de ella misma vestida de múltiples formas que sube a su cuenta Instagram ${ }^{4}$ para-traducir una serie de connotaciones simbólicas con cada nueva imagen de beurette con el fin de crear todo un nuevo imaginario de lo que ella llama la beurettocracie $\mathrm{o}$ aristrocratie des beurettes. El procedimiento paratraductivo de esta activista feminista francesa consiste en una serie de paratraducciones intersemióticas visuales de complementos de lujo (ropa, calzado, anillos, collares, fulares), por un lado, y complementos supuestamente vulgares, por otro, a los cuales les cambia el valor el símbólico para-traducir, de forma permanente, el mestizaje de los dos códigos culturales que conforman las dos pertenencias de su identidad mestiza: la francesa, por un lado, y la argelina, por otro, en su caso. Estamos ante un ejemplo práctico

3. Véase el vídeo titulado Lisa Bouteldja déconstruit les clichés autour des femmes d’origine magbrébine y editado por Brut en Youtube https://youtu.be/jALTxKrBGU4

4. https://www.instagram.com/lisabouteldja/ 
y no cabe más social de transculturalidad intrapersonal para-traducir la identidad mestiza. Tal y como Jacques Derrida decía sentirse europeo «à part entière» pero rechazaba sentirse europeo «de part en part» cuando hablaba de las expresiones «à part entière» $\mathrm{y}$ «de part en part» (DERRIDA, 2002, p. 80) porque, entonces, toda su identidad se reduciría a esa única pertenencia (se trataría de ser europeo siempre plenamente para no serlo nunca integralmente), la activista feminista Lisa Bouteldja se siente $100 \%$ francesa y $100 \%$ magrebí... «à part entière».

Recordemos con François Laplantine y Alexis Nouss que el mestizaje es siempre lo primero y corresponde a la lógica de lo vivo y, por consiguiente, al encuentro de culturas (LAPLANTINE y NOUSS, 1997, p. 71-72). El mestizaje en traducción no es ni un concepto ni una etiqueta, sino una disposición a pensar que toda cultura es como un mosaico hecho de multitud de piezas provenientes de distintos registros. El mestizaje es, ante todo, un estado de cultura, un universo mental íntimamente unido a las tomas de decisión de familias que han vivido la experiencia de la emigración, del exilio, del viaje. La población francesa, como cualquier otra del mundo, ha nacido y se ha desarrollado a lo largo de la historia gracias al mestizaje de pueblos autóctonos con gente que venía de otros territorios, de otros países, de otros continentes. No es la sangre la que define la identidad sino las lenguas, las culturas, los costumbres, los ritos, las tradiciones que mantienen vivas a las personas. Entender la traducción como mestizaje de culturas implica romper con las ideas clásicas que durante siglos han ido forjando la propia noción identidad mal entendida por quienes han despreciado siempre el paradigma de la traducción en la construcción de la misma (YUSTE FRÍAS, 2015a).

\section{A MODO DE CONCLUSIÓN: TRADUCIR «LO INTRADUCIBLE»}

Barbara Cassin, filósofa, filóloga, helenista por supuesto, pero también militante de la diversidad cultural cuando se trata de gestionarla con la población migrante desde la posición siempre activista de su constante y omnipresente elogio de la traducción (CASSIN, 2016), define así lo que es un «intraducible» en la primera página de presentación de su obra magna, el famoso Vocabulaire européen des philosopbies. Dictionnaire des intraduisibles (CASSIN, 2014) que no debería faltar nunca en la biblioteca de toda persona que se dedica a traducir e interpretar:

Parler d'intraduisibles n'implique nullement que les termes en question, ou les expressions, les tours syntaxiques et grammaticaux, ne soient pas traduits et ne puissent pas l'être l'intraduisible, c'est plutôt ce qu'on ne cesse pas de (ne pas) traduire. Mais cela signale que leur traduction, dans une langue ou dans une autre, fait problème, au point de susciter parfois un néologisme ou l'imposition d'un nouveau sens sur un vieux mot : c'est un indice 
de la manière dont, d'une langue à l'autre, tant les mots que les réseaux conceptuels ne sont pas superposables [...] (CASSIN, 2014, pp. XVII- XVIII. La cursiva es de la autora y la negrita es nuestra)

«Lo intraducible» no es lo que no traducimos porque no podemos, sino todo lo contrario. Lo «intraducible» es todo aquello sobre lo que nunca dejamos de trabajar para traducirlo, cada vez, mejor. Lo «intraducible» es lo que no dejamos nunca de (no) traducir en el mercado profesional de la traducción y la interpretación. Desde la primera línea de este artículo hasta la última hemos ido practicando la traducción de «lo intraducible»: no hemos dejado de traducir las palabras francesas beur y beurette, pero lo hemos hecho sin ofrecer, en ningún momento, una palabra en español que fuera su definitiva traducción. Al contrario, al estar ante dos «intraducibles», hemos usado los propios términos franceses como préstamos en la lengua española y no nos hemos cansado de explicitar, de glosar y de interpretar todos y cada uno de los usos que esos dos términos tienen en la lengua francesa desde los años 80 hasta hoy. Los «intraducibles» beur y beurette nos han hecho tomar conciencia de que la traducción, contrariamente a lo que suele pensarse, no es sólo mera transferencia o paso de una lengua a otra. Al contrario, intentar traducir los «intraducibles» beur y beurette nos ha enseñado lo difícil que resulta la experiencia liminar del umbral en traducción. Al revalorizar el umbral y desmarginalizar el margen en traducción, la noción de paratraducción instaura esa experiencia liminar del umbral tan olvidada en la concepción de la traducción concebida, sólo y exclusivamente, como puente, paso, transferencia o circulación entre lenguas y culturas (YUSTE FRÍAS, 2015b, p. 341). Y es que, en realidad, el propio traductor es «para-», es la frontera misma, el umbral de una puerta entre lo conocido y lo desconocido, el margen del espacio intermediario situado «entre» lenguas y culturas (YUSTE FRÍAS, 2015b, p. 333-334). Barbara Cassin resume en una sola frase este posicionamiento filosófico, ideológico, social, cultural y político del «entre» que fomenta el Grupo de Investigación Traducción \& Paratraducción $(\mathrm{T} \& \mathrm{P})$ de la Universidade de Vigo, invitando a todo profesional de la traducción y la interpretación que se precie «à pratiquer la gymnastique du "entre" et à compliquer l'universel» 5 (CASSIN, 2016, p. 25).

Porque no podemos comprender todo al instante, con la noción de «lo intraducible» magistralmente apuntada por Barbara Cassin, pasar de una lengua a otra supone aceptar permanecer «entre» lenguas el tiempo que haga falta hasta lograr hacer pasar un mundo en otro mundo. A lo largo de este artículo, hemos practicado la gimnasia del «entre»y hemos complicado todo lo que podía haber

5. «a practicar la gimnasia del "entre" y a complicar lo universal» Mi trad. esp. 
de universal en beur y beurette. De hecho, hemos ido dando más de una pista, más de un síntoma de las diferencias de uso de los términos beur y beurette en francés para traducir las distintas pertenencias de la identidad de una muy determinada población francesa reducida a beurre («mantequilla») por la perspectiva intercultural de integración absoluta preconizada por la República francesa (YUSTE FRÍAS, 2018a).

La traducción como pensamiento y como práctica de un «entre»implica no concebir nunca la lengua como un lugar de identidad permanente, sino siempre como un «lugar de identidad temporal» (CASSIN, 2018) en el que quien habla se busca a sí mismo en cada acto de habla. Usar los términos beur y beurette para-traducir la identidad de la persona nacida en Francia de padres inmigrantes magrebíes debería implicar siempre hacer referencia a una muy determinada identidad que, al estar construida en una especie de bilingüismo latente en una misma lengua es, además de temporal, mestiza.

Le métissage, qui est une espèce de bilinguisme dans la même langue et non la fusion de deux langues, suppose la rencontre et l'échange entre deux termes comme c'est le cas aujourd'hui pour la culture beur. Non pas l'un ou l'autre (l'arabité ou l'appartenance à la France seulement), mais l'un et l'autre : l'un ne devenant pas l'autre, ni l'autre ne se résorbant dans l'un. (LAPLANTINE y NOUSS, 1997, p. 79. La cursiva es de los autores)

Beur y beurette resultan ser dos intraducibles que nos enseñan que el mestizaje no debe confundirse nunca con la mezcla (que tiene que ver con la fusión) ni, mucho menos, con la hibridación (que produce un nuevo conjunto). El mestizaje tiene que ver con el desequilibrio, la duda permanente. De la misma forma que el devenir jamás se adivina, el devenir de la identidad mestiza expresada por los términos beur y beurette es tan irreversible como imprevisible e inestable, jamás acaba, jamás es definitivo. Como en todo mestizaje, en los términos franceses beur y beurette cada pertenencia conserva su propia historia sin perder ni un ápice de la misma. En definitiva, la identidad mestiza sigue una aritmética muy poco ortodoxa en la concepción de la identidad: el joven beur o la joven beurette, de origen magrebí, no es mitad francés o francesa (50\%) y mitad magrebí (50\%), como quiere que lo sean la uniformización intercultural republicana (YUSTE FRÍAS, 2018a) o el diferencialismo multicultural (YUSTE FRÍAS, 2018b). Beur y beurette son $100 \%$ francés o francesa y $100 \%$ magrebí en un devenir mestizo de la identidad que, lejos de ser simple, monocroma y homogénea (como cuando el racista y extremista de turno identifica identidad con una sola pertenencia), aparece, a los ojos y los oídos de todo el mundo, compuesta por múltiples pertenencias. El Magreb, «el lugar donde se pone el sol»-ese sol que derrite la mantequilla a la que Francia 
pretende reducir la identidad mestiza de las personas que descienden de aquellas que vivieron en sus antiguas colonias- no está formado por una sola cultura. Son varios los países, las ciudades y las zonas geográficas que conforman el Magreb (Argelia, Libia, Mauritania, Marruecos, Túnez, Sáhara Occidental, Ceuta y Melilla) $\mathrm{y}$, por consiguiente, varias las culturas que ofrecen distintas pertenencias para construir, a más de $200 \%$, en una aritmética del mestizaje nada ortodoxa ${ }^{6}$ y gracias a una transculturalidad permanente tan positiva como nada peyorativa, la identidad mestiza del beur y de la beurette en Francia.

\section{REFERENCIAS}

BLANCHARD, Pascal ${ }_{i}$ BANCEL, Nicolas; BOETSCH, Gilles; THOMAS, Dominic; TARAUD, Christelle [eds.]. (2018). Sexe, race \& colonies. La domination des corps $d u X V^{e}$ siècle à nos jours, Paris: La Découverte.

CASSIN, Barbara. (2018). La Nostalgie: Quand donc est-on chez soi ?. Paris: Autrement.

CASSIN, Barbara. (2016). Éloge de la traduction. Compliquer l'universel. Paris: Fayard.

CASSIN, Barbara [dir.]. (2014). Vocabulaire européen des philosophies. Dictionnaire des intraduisibles, Paris: Seuil-Le Robert.

DERRIDA, Jacques. (2002). L'Autre Cap, Paris: Galilée.

DESPLANQUES, François. (1997). A.N.I., Beurs et compagnie ou comment diable les nommer ? Cabiers de la Méditerranée, $n^{\circ} 54,1$. Mots et migrations [Actes du colloque de Grasse, novembre 1996], pp. 237-244. Disponible en red: https://doi.org/10.3406/ camed.1997.1189

LAPLANTINE, François ; NUSELOVICI (NOUSS), Alexis. (1997). Le métissage. Un exposé pour comprendre. Un essai pour réféchir, Paris: Flammarion.

6. Aritmética nada ortodoxa del mestizaje que también puede practicarse en Brasil para-traducir la identidad mestiza de toda persona nacida en ese país. «L'arithmétique du métissage n'est guère orthodoxe. Elle ne reprend pas le déconpage binaire des byphenated identities (identités au trait d'union) nord-américaines : afroaméricain, italo-américain,... Pour reprendre l'exemple classique du sujet brésilien auquel sont reconnues des origines indienne, africaine et européenne, el peut se revendiquer indien et européen, africain et indien, européen et africain, ou les trois à la fois. Dans ce dernier cas, il n'est pas un tiers Indien, un tiers Africain et un tiers Européen, il est cent pour cent Indien, cent pour cent Africain et cent pour cent Européen. C'est-à-dire qu'il est Indien, Africain et Européen tout à tour, et pleinement à chaque fois; il est ce qu'il est à $300 \%$ !» (NOUSS, 2005, p. 35) 
LIAUZU, Claude. (1997). Mots et migrants méditerranéens Cabiers de la Méditerranée, n. ${ }^{\circ} 54$, 1, pp. 1-14. Disponible en red: https://doi.org/10.3406/camed.1997.1171

NUSELOVICI (NOUSS), Alexis. (2005). Plaidoyer pour un monde métis, París: Textuel.

TOURNIER, Maurice. (2002). D'arbicot à beur: des mots tordus Langages. Des mots en politiques Propos d'étymologie sociale, tome 2, pp. 15-19. Disponible en red: https://books. openedition.org/enseditions/1703

YUSTE FRÍAS, José. (2018c). Traduire et interpréter le migrant III : partager une paëlla Sur les seuils du traduire. Un carnet de recherche sur la traduction et la paratraduction, Marsella-ParísLisboa: Hypothèses_OpenEdition_Centre pour l'édition électronique ouverte (Cléo)_CNRS_EHESS_Université d'Aix-Marseille_Université d'Avignon [en red], entrada del 31/05/2018: https://seuils.hypotheses.org/1950

YUSTE FRÍAS, José. (2018b). Traduire et interpréter le migrant II : s'attarder au buffet à volonté Sur les senils du traduire. Un carnet de recherche sur la traduction et la paratraduction, Marsella-París-Lisboa: Hypothèses_OpenEdition_Centre pour l'édition électronique ouverte (Cléo)_CNRS_EHESS_Université d'Aix-Marseille_ Université d'Avignon [en red], entrada del 07/05/2018: https://seuils.hypotheses. org/1948

YUSTE FRÍAS, José. (2018a). Traduire et interpréter le migrant I : avaler une purée de légumes Sur les senils du traduire. Un carnet de recherche sur la traduction et la paratraduction, MarsellaParís_Lisboa: Hypothèses_OpenEdition_Centre pour l'édition électronique ouverte (Cléo)_CNRS_EHESS_Université d'Aix-Marseille_Université d'Avignon [en red], entrada del 09/04/2018: https://seuils.hypotheses.org/1858

YUSTE FRÍAS, José. (2017). Identité culturelle et TIMS Sur les seuils du traduire. Un carnet de recherche sur la traduction et la paratraduction, Marsella-París-Lisboa: Hypothèses OpenEdition_Centre pour l'édition électronique ouverte (Cléo)_CNRS_EHESS Université d'Aix-Marseille_Université d'Avignon [en red], entrada del 05/09/2017: http://seuils.hypotheses.org/1760

YUSTE FRÍAS, José. (2016). Por una comunicación transcultural en los servicios públicos de traducción e interpretación. In: FERREIRO VÁZQUEZ, Óscar [ed.]. Traducir e interpretar lo público. Granada: Comares, pp. 105-119. Disponible en red: https://www. academia.edu/30580393/Por_una_comunicaci\%C3\%B3n_transcultural_en_los servicios_p\%C3\%BAblicos_de_traducci\%C3\%B3n_e_interpretaci\%C3\%B3n 
YUSTE FRÍAS, José. (2014). Realidad profesional de la industria de la traducción y falacia de la competencia nativa. In: MONTERO DOMÍNGUEZ, Xoán [ed.] Traducción e industrias culturales. Nuevas perspectivas de análisis, Frankfurt am Main-Bern-BruxellesNew York: Oxford-Warszawa-Wien: Peter Lang, Col. Studien zur romanischen Sprachwissenschaft und interkulturellen Kommunikation, dirigida por Gerd Wotjak, vol. 96, pp. 77-91. Disponible en red: https://www.academia.edu/7683293/ Realidad_profesional_de_la_industria_de_la_traducci\%C3\%B3n_y_falacia_de_la_ competencia_nativa

YUSTE FRÍAS, José. (2015b). Paratraducción: la traducción de los márgenes, al margen de la traducción. DELTA: Revista de Documentação de Estudos em Lingüística Teórica e Aplicada, vol. 31, special issue, pp. 317-347. Disponible en red: https://www.scielo.br/pdf/ delta/v31nspe/1678-460X-delta-31-spe-00317.pdf

YUSTE FRÍAS, José. (2015a). La traduction comme métissage des cultures Sur les seuils du traduire. Un carnet de recherche sur la traduction et la paratraduction, Marsella-París-Lisboa: Hypothèses_OpenEdition_Centre pour l'édition électronique ouverte (Cléo) CNRS_EHESS_Université d'Aix-Marseille_Université d'Avignon [en red], entrada del 06/11/2015: https://seuils.hypotheses.org/1405

YUSTE FRÍAS, José. (2013). Identité et traduction Sur les seuils du traduire. Un carnet de recherche sur la traduction et la paratraduction, Marsella-París-Lisboa: Hypothèses_OpenEdition_ Centre pour l'édition électronique ouverte (Cléo)_CNRS_EHESS_Université d'Aix-Marseille_Université d'Avignon [en red], entrada del 24/05/2013: https:// seuils.hypotheses.org/785

Recebido: 24/7/2020

Aceito: 27/7/2020

Publicado: 29/7/2020 